\title{
PERANCANGAN SISTEM APLIKASI PEMESANAN MAKANAN DI AYAM BAKAR PAK MUL BERBASIS MOBILE ANDROID
}

\author{
Lutfi Nuranggang ${ }^{1}$, Tri Yani Akhirina ${ }^{2}$ \\ Program Studi Informatika, Fakultas Teknik dan Ilmu Komputer, Universitas Indraprasta PGRI \\ Jalan Raya Tengah No 80, Kelurahan Gedong, Pasar Rebo, Jakarta Timur \\ Lutfianggang@gmail.com¹, Azizahputriku@gmail.com²
}

\begin{abstract}
Abstrak
Munculnya berbagai macam aplikasi meningkatkan suatu pekerjaan, baik yang bersifat desktop dan web hingga muncul aplikasi baru yang berjalan di sistem mobile android. Pemilihan mobile android untuk pengembangan aplikasi karena mudah dan fleksibel. Sistem pemesanan makanan di Ayam Bakar Pak Mul masih menggunakan sistem manual, untuk memesan pelanggan datang menemui kasir dan kasir mencatat pesanan yang ingin dibungkus. Berdasarkan masalah yang terjadi maka harus dibuat aplikasi pemesanan makanan yang berbasis mobile android. Untuk memudahkan pelanggan maka harus dibuat tampilan yang mudah dipahami dan pelanggan harus mendaftar agar tidak ada kasus penipuan. Penggunaan mobile android untuk Ayam Bakar Pak Mul akan memudahkan proses pemesanan oleh pelanggan, karena pelanggan langsung terhubung dengan bagian kasir sehingga informasi tentang makanan diketahui oleh pelanggan. Aplikasi android dibangun menggunakan bahasa pemrograman Java android dihubungkan dengan database Firebase yang bersifat cloud dan selalu update. Aplikasi dibangun menggunakan lowchart dengan metode penelitian R\&D.
\end{abstract}

Kata Kunci: Perancangan Sistem, Pemesanan, Android, Firebase

\begin{abstract}
The emergence of a wide range of applications improves a job, both desktop and web until a new app running on the android mobile system appears. Android mobile selection for app development because it is easy and flexible. The food ordering system at Ayam Bakar Pak Mul still uses a manual system, to order customers to come to see the cashier and the cashier records the order that you want to wrap. Based on the problem that occurs then should be created food ordering app based on mobile android. To make it easier for customers, there must be an easy-to-understand view and customers must register so that there are no cases of fraud. The use of android mobile for Ayam Bakar Pak Mul will facilitate the customer's ordering process, because the customer is directly connected to the cashier so that information about food is known to the customer. Android apps built using the Android Java programming language are connected to firebase databases that are cloud and always up to date. Applications are built using lowchart with $R \& D$ research methods.
\end{abstract}

Keyword: System Planning, Ordering, Android, Firebase

\section{PENDAHULUAN}

Perkembangan teknologi yang sangat pesat telah banyak memberikan manfaat dalam kehidupan, diantaranya adalah komputer, internet, bahkan alat telekomunikasi yang semakin canggih. Dengan adanya ketiga elemen tersebut, telah banyak membantu untuk mengolah data dan dalam berkomunikasi yang tidak lagi dibatasi oleh jarak dan waktu bahkan tempat yang jauh sekalipun. Salah satu teknologi itu adalah telepon pintar, telepon pintar (smartphone) mempunyai kemampuan tinggi dengan fungsi yang hampir menyerupai komputer.

Beberapa orang mengatakan, smartphone merupakan perangkat mobile yang sangat bergantung kepada perangkat lunak (software) dari sistem operasi yang telah menyediakan berbagai standar dan kemudahan bagi pengembang aplikasi tersebut. Bagi sebagian orang yang lain, smartphone merupakan sebuah telepon yang menyajikan fitur canggih dan terbaru yang belum ada sebelumnya seperti e-mail, internet dan kemampuan membaca buku elektronik/e-book.

Perkembangan teknologi pada era ini telah memberikan pengaruh yang sangat besar bagi dunia teknologi informasi dan telekomunikasi. Munculnya berbagai macam aplikasi memberikan banyak pilihan dalam mempermudah pekerjaan, baik bersifat desktop dan web hingga yang sekarang ini 
muncul banyak aplikasi yang berjalan dalam smartphone seperti pada sistem operasi android. Pemilihan sistem operasi android untuk salah satu pengembangan aplikasi selain lebih mudah dalam perngoperasiannya, dan juga sifat dari smartphone yang fleksibel.

Sistem pemesanan makanan di Ayam Bakar Pak Mul masih menggunakan cara manual untuk memesan makanan, pelanggan datang menemui kasir dan kasir mencatat pesanan yang ingin dibungkus, sehingga pelanggan cukup membuang waktu dan tenaga untuk datang memesan. Berdasarkan masalah yang terjadi maka harus dibuat aplikasi pemesanan makanan yang berbasis mobile android. Menurut (Abdurahman\&Riswaya, 2014) Aplikasi adalah suatu program yang bisa digunakan untuk menjalankan perintah dari pengguna aplikasi tersebut dengan tujuan mendapatkan hasil yang lebih akurat, cepat dan lebih mudah sesuai dengan tujuan pembuatan aplikasi tersebut, aplikasi mempunyai arti pemecahan masalah yang menggunakan salah satu teknik pemrosesan data, aplikasi biasanya berpacu pada sebuah program untuk mendapat hasil yang diinginkan atau diharapkan. Sedangkan Android menurut (Safaat, 2011) adalah sistem operasi untuk smartphone berbasis linux yang mencakup sistem operasi, middleware dan aplikasi. Android adalah platform terbuka yang memungkinkan pengembang menciptakan aplikasi mereka. Android di distribusikan dengan dua jenis. Pertama yang mendapat dukungan penuh dari google atau Google Mail Service (GMS). Kedua adalah yang tidak mendapatkan dukungan secara langsung dari google atau Open Handset Distribution (OHD).

Tujuan penelitian ini adalah merancang aplikasi yang dapat memudahkan pelanggan dapat mengetahui makanan apa yang ada dan juga mendapat rincian biaya yang tepat serta memudahkan pelanggan agar tidak perlu repot datang ke tempat untuk memesan. Sedangkan manfaat dari penelitian ini adalah dengan adanya sistem pemesanan makanan di Ayam Bakar Pak Mul berbasis mobile android diharapkan dapat meningkatkan pemasukan bagi Ayam Bakar Pak Mul.

\section{PENELITIAN RELEVAN}

Penelitian oleh (Inpuwati, 2014) dengan judul Perancangan Sistem Informasi Penjualan Pada Toko Minak Singa, Toko Minak Singa adalah salah satu Toko yang telah berdiri sejak tahun 2010 di Desa Kedondong Kabupaten Pesawaran Provinsi Lampung. Mekanisme sistem penjualan sekarang masih menggunakan sistem konvensional, dimana konsumen harus datang langsung ke outlet atau melalui sales marketing. Dengan adanya Sistem Informasi pada Toko Minak Singa diharapkan dapat memberikan kemudahan kepada masyarakat untuk melakukan pembelian produk tanpa harus datang ke tempatnya, serta memperluas pemasaran dan meningkatkan costumer loyality. Usaha ini dikembangkan dengan SDLC (System Development Life Cycle) dan software yang digunakan untuk merancang dan mendesain Aplikasi yaitu bahasa pemrograman PHP dan Database MySQL. Aplikasi ini juga dapat menghasilkan informasi produk yang dijual, serta menyajikan laporan-laporan yang ditujukan kepada pemilik (owner) diantaranya: laporan produk, laporan outlet, laporan order, dan laporan penjualan.

Penelitian relevan selanjutnya oleh (Nugraha et al., 2014) dengan judul Aplikasi Pemesanan Makanan Berbasis Mobile Pada Rumah Makan "Lek Nonong". Bisnis restoran itu mulai berkembang di Semarang khususnya di daerah Tembalang. Berbagai jenis makanan dan minuman ditawarkan oleh restoran. Tentu saja, untuk dapat bersaing restoran perlu manajemen yang baik dalam upaya memperoleh manfaat yang optimal. Berdasarkan masalah perlu mengembangkan Aplikasi Berbasis Mobile Pesanan Makanan untuk mendukung proses kerja restoran, terutama dalam proses pemesanan dan melaporkan menu transaksi. Aplikasi seluler dibangun menggunakan bahasa pemrograman jQuery Mobile dan HTML. Penggunaan aplikasi seluler didukung oleh aplikasi yang berjalan pada komputer desktop yang dibangun menggunakan bahasa pemrograman PHP, Javascript dan database MySQL. Aplikasi pemodelan dibangun menggunakan DFD (Data Flow Diagram). Hasil perancangan Aplikasi Aplikasi Berbasis Mobile Food adalah aplikasi yang dapat digunakan untuk proses kerja dan mengelola laporan transaksi di restoran, dan juga aplikasi yang dapat digunakan untuk masuk ke menu pemesanan menggunakan perangkat seluler. 


\section{METODE PENELITIAN}

Metode penelitian yang dilakukan oleh peneliti merupakan jenis penelitian pengembangan atau Research and Development (R\&D). Menurut (Sugiyono, 2012) Metode penelitian R\&D adalah metode penelitian yang digunakan untuk menghasilkan produk tertentu, dan menguji keefektifan produk tersebut. Sedangkan Menurut (Sukmadinata, 2010) Penelitian R\&D adalah suatu proses atau langkah-langkah untuk mengembangkan suatu produk baru atau menyempurnakan produk yang telah ada. Produk yang dimaksud tidak semuanya harus berbentuk benda atau perangkat keras (hardware) contohnya seperti buku, modul, alat bantu pembelajaran dikelas atau di laboratorium. Tapi bisa juga berupa perangkat lunak (software) seperti program smartphone untuk mengolah data, sistem belajar di kelas, perpustakaan, ataupun model-model pendidikan, pembelajaran, pelatihan, bimbingan, evaluasi dan lain-lain.

Guna mendapatkan data yang dibutuhkan dalam penelitian ini, metode pengumpulan data serta informasi untuk mendukung penyempurnaan hasil dari penelitian ini, peneliti menggunakan beberapa metode, antara lain adalah:

a. Observasi

Peneliti mengadakan kunjungan langsung kerumah makan Ayam Bakar Pak Mul untuk memperoleh data secara akurat dan memperoleh gambaran sistemberjalan yang tepat

b. Wawancara

Peneliti melakukan tanya jawab langsung kepada narasumber diantaranya Pemilik, karyawan, maupun pihak lain yang berkaitan langsung dalam pelayanan penjualan.

c. Kepustakaan

Peneliti juga melakukan studi kepustakaan dengan menggunakan buku yang dapat dijadikan referensi dan juga internet, guna menunjang informasi yang dibutuhkan dalam penelitian ini..

Metodologi pengembangan sistem yang digunakan adalah Waterfall, metode waterfall sering dinamakan siklus hidup klasik (classic life cycle), metode waterfall dimulai dengan spesifikasi kebutuhan pengguna lalu berlanjut melalui tahapan-tahapan perencanaan (planning), permodelan (modeling), konstruksi (construction), serta penyerahan sistem ke para pelanggan/pengguna (.deployment), yang diakhiri dengan dukungan pada perangkat lunak lengkap yang dihasilkan (Pressman, 2009). Tahapan metode waterfall dapat kita lihat pada gambar di bawah:

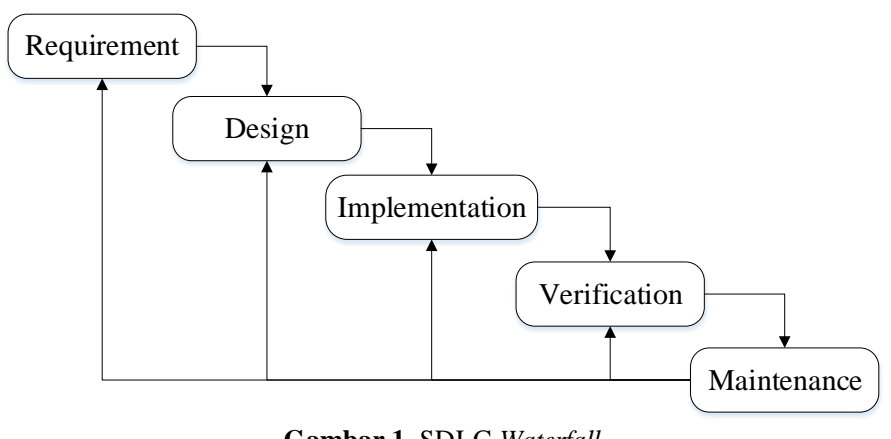

Gambar 1. SDLC Waterfall

\section{Requirement Analisis}

Tahap ini pengembang sistem memerlukan komunikasi yang bertujuan untuk memahami perangkat lunak yang diharapkan oleh pengguna dan batasan perangkat lunak tersebut. Informasi ini biasanya dapat diperoleh melalui wawancara, diskusi atau survei langsung

2. System Design

Spesifikasi kebutuhan dari tahap sebelumnya akan dipelajari dalam fase ini dan desain sistem akan disiapkan. Desain Sistem membantu dalam pemilihan perangkat keras(hardware), standar sistem dan juga membantu dalam mendefinisikan arsitektur sistem secara keseluruhan. 


\section{Implementation}

Pada tahap ini, sistem pertama kali dikembangkan di program kecil yang disebut unit, yang terintegrasi dalam tahap selanjutnya. Setiap unit dikembangkan dan diuji untuk fungsionalitas yang disebut sebagai unit testing.

4. Integration \& Testing

Seluruh unit yang dikembangkan dalam tahap implementasi diintegrasikan ke dalam sistem setelah pengujian yang dilakukan masing-masing unit. Setelah integrasi seluruh sistem diuji untuk mengecek setiap kegagalan maupun kesalahan.

5. Operation \& Maintenance

Tahap akhir dalam model waterfall. Perangkat lunak yang sudah jadi, dijalankan serta dilakukan pemeliharaan. Pemeliharaan termasuk dalam memperbaiki kesalahan yang tidak ditemukan pada langkah sebelumnya.

\section{HASIL DAN PEMBAHASAN}

\section{Flowchart Sistem}

Menurut (Indrajani, 2011) Flowchart merupakan penggambaran secara grafik dari langkah-langkah dan urutan prosedur suatu program, Biasanya mempengaruhi penyelesaian masalah yang khusunya perlu dipelajari dan dievaluasi lebih lanjut. Sedangkan menurut Ladjamudin (2013) flowchart adalah bagan - bagan yang mempunyai arus yang menggambarkan langkah - langkah penyelesaian suatu masalah. Berikut ini adalah Flowchart dari Perancangan Sistem Aplikasi Pemesanan Makanan Di Ayam Bakar Pak Mul Berbasis Mobile Android:

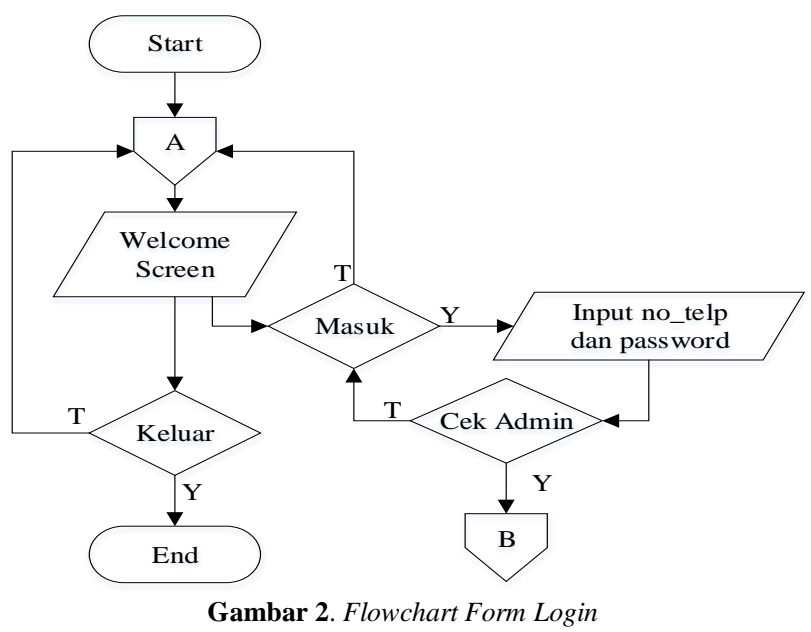

Tampilan awal ketika memasuki aplikasi pengguna harus memilih, jika pengguna sudah mempunyai akun maka pengguna dapat langsung memilih tombol Sign in, setelah itu memasukan no_telp dan juga password, selanjutnya memilih tombol login dan jika no_telp dan password benar maka akan berpindah ke halaman beranda, jika password salah muncul pesan peringatan bahwa password salah, jika no_telp salah maka muncul pesan peringatan akun tidak ada. Jika belum mempunyai akun, pilih tombol Sign Up maka pengguna pindah ke halaman daftar dan menambahkan data. 


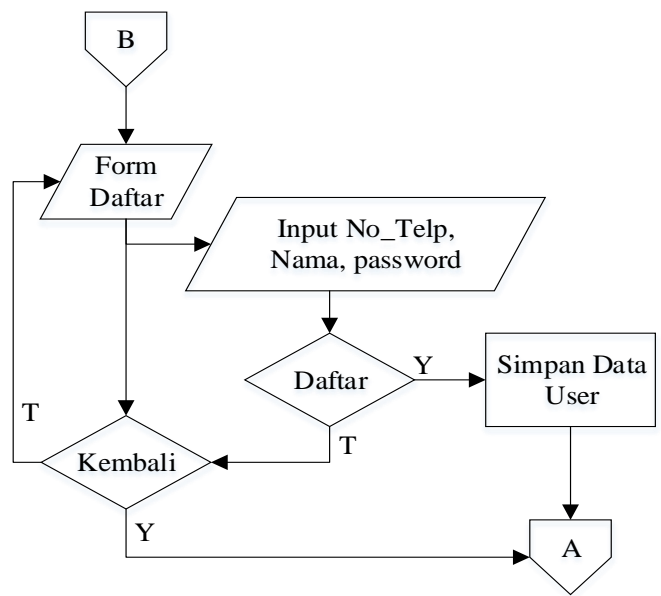

Gambar 3. Flowchart Form Daftar

Pengguna mengisi data yang dibutuhkan seperti no_telp, nama, password. Setelah data diisi selanjutnya pengguna akan kembali ke halaman utama, dan harus memilih tombol sign in untuk login

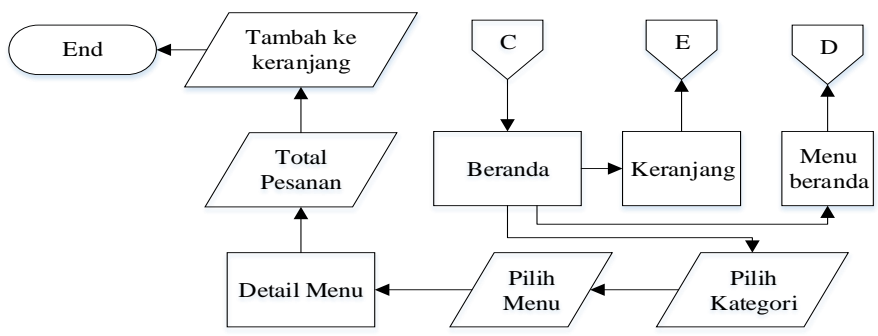

Gambar 4. Flowchart Form Beranda \& Memesan Menu

Program akan menampilkan daftar kategori yang tersedia yang sudah ditambahkan oleh admin, Jika pengguna memilih kategori maka akan masuk ke daftar menu, Jika pengguna memilih salah satu menu maka akan masuk ke informasi makanan, pemesanan makanan dan jumlah pesanan, Jika pengguna memilih tombol menu beranda, maka pengguna akan beralih ke menu beranda, Jika pengguna memilih tombol bergambar keranjang, maka pengguna akan beralih ke halaman keranjang

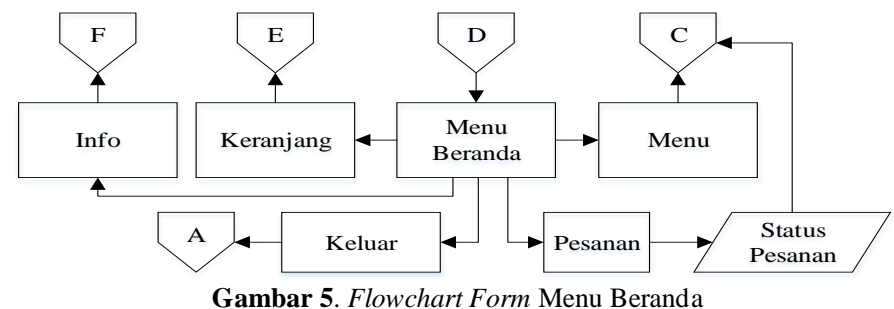

Menampilkan nama pembeli, tombol menu, tombol keranjang, tombol pesanan, dan tombol keluar, Jika memilih tombol menu, maka tampilan beralih ke beranda, Jika memilih tombol keranjang, maka tampilan beralih ke halaman keranjang, Jika memilih tombol pesanan, maka tampilan beralih ke halaman pesanan yang berisi nomor pesanan, status pesanan, no_telp, alamat dan tanggal pemesanan, Jika memilih tombol info, maka tampilan beralih ke halaman informasi, Jika memilih tombol keluar, maka tampilan akan beralih ke form login. 


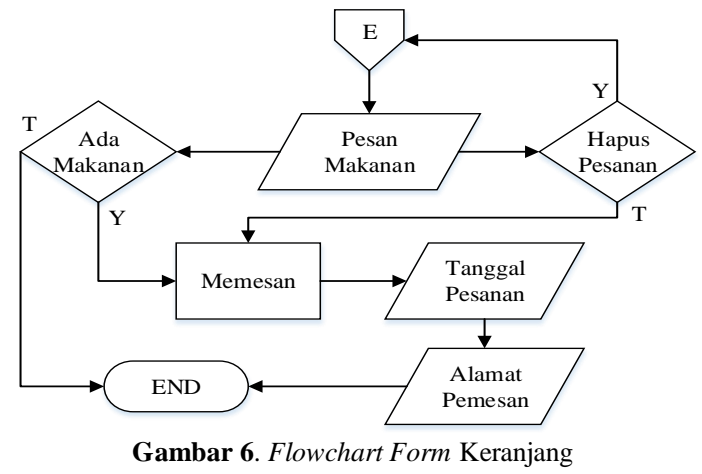

Disini dapat melihat makanan pesanannya, jika ada kesalahan pemesanan dapat menahan nama pesanan dan pilih tombol hapus untuk menghapus pesanan, Jika pesanan sudah benar maka bisa melakukan pemesanan dengan memasukan tanggal dan alamat lengkap rumah dengan jelas dan kembali ke beranda

\section{Tampilan Database Firebase}

Menurut (Suharyanto et al., 2014) Database adalah kumpulan data terstruktur. Agar dapat menambahkan, mengakses, dan memproses data yang tersimpan dalam database komputer, dibutuhkan sistem manajemen basis data (database management system).

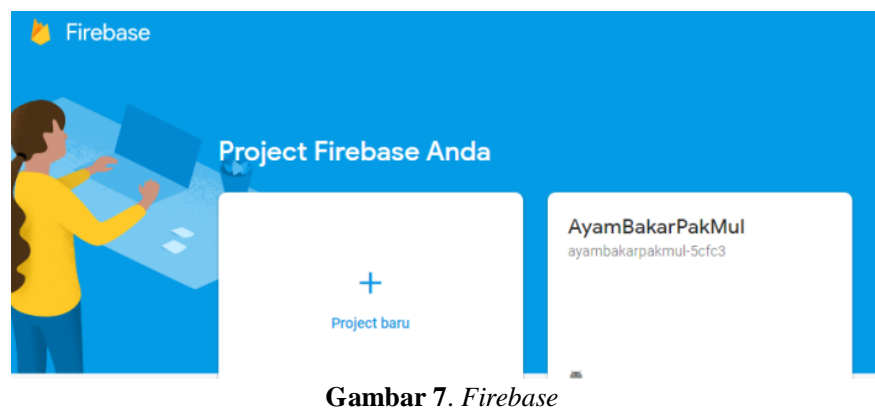

\section{Uji Coba di Perangkat Smartphone}

Uji Coba dengan perangka dilakukan untuk melihat kekurangan dari aplikasi jika di jalankan dengan perangkat smartphone. Dari uji coba yang sudah dilakukan berikut kesimpulan hasil yang didapat dari proses uji coba:

Tabel 1. Uji coba program dengan Smartphone

\begin{tabular}{ccccccc}
\hline No. & Merek & Tipe & Versi OS & Instalasi & Kualitas Gambar & Error \\
\hline 1 & Xiaomi & Redmi 4x & 7.1 .2 & Berhasil & Sangat Baik & Tidak Ada \\
2 & Oppo & F5 & 7.1 .1 & Berhasil & Sangat Baik & Tidak Ada \\
3 & Xiaomi & Redmi Note 4x & 7.1 .2 & Berhasil & Sangat Baik & Tidak Ada \\
4 & Vivo & Y91 & 8.1 .0 & Berhasil & Sangat Baik & Tidak Ada \\
\hline
\end{tabular}

\section{SIMPULAN}

Berdasarkan hasil dari pembahasan yang telah diuraikan sebelumnya dan menyesuaikan dari rumusan masalah yang ada, maka kesimpulan yang diperoleh peneliti adalah sebagai berikut:

1. Dengan dibuatnya sistem aplikasi penjualan dapat memudahkan admin dalam melayani proses pemesanan dan penjualan yang biasanya dilakukan dengan cara manual. 
2. Dengan dibuatnya aplikasi penjualan dapat memudahkan pelanggan dalam memesan, karna tidak perlu datang untuk memesan makanan dan menunggu terlalu lama

3. Memudahkan pelanggan dalam proses pemesanan dengan tampilan yang interaktif, proses pemesanan yang mudah serta menampilkan pemesanan yang sudah dilakukan sebelumnya.

4. Memudahkan pelanggan dalam melakukan pemesanan dengan tampilan yang mudah dipahami dan digunakan, sehingga memberikan pengalaman yang menarik untuk pelanggan

\section{DAFTAR PUSTAKA}

Abdurahman, H., \& Riswaya, A. R. (2014). Aplikasi Pinjaman Pembayaran Secara Kredit. Jurnal Computech \& Bisnis, 8(2), 61-69.

Indrajani, I. (2011). Perancangan Sistem Basis Data pada Klinik. ComTech: Computer, Mathematics and Engineering Applications, 2(1), 218. https://doi.org/10.21512/comtech.v2i1.2737

Inpuwati, S. (2014). Perancangan Sistem Informasi Penjualan Pada Toko Minak Singa. Explore: Jurnal Sistem Informasi Dan Telematika, 4(2).

Nana Syaodih Sukmadinata, A. \&. (2010). PENGEMBANGAN MODEL PEMBELAJARAN TERPADU BERBASIS BUDAYA UNTUK MENINGKATKAN APRESIASI SISWA TERHADAP BUDAYA LOKAL. Jurnal Cakrawala Pendidikan. https://doi.org/10.21831/cp.v2i2.339

Nathan, A. J., \& Scobell, A. (2012). How China sees America. Foreign Affairs, 91(5). https://doi.org/10.1017/ CBO9781107415324.004

Nugraha, A. P., Satoto, K. I., \& Martono, K. T. (2014). Aplikasi Pemesanan Makanan Berbasis Mobile Pada Rumah Makan "Lek Nonong." Jurnal Teknologi Dan Sistem Komputer, 2(2), 175-180. https://doi.org/10.14710/JTSISKOM. 2.2.2014.175-180

Pressman, R. S. (2009). Software Engineering A Practitioner's Approach 7th Ed - Roger S. Pressman. In Software Engineering A Practitioner's Approach 7th Ed - Roger S. Pressman. https://doi.org/10.1017/CBO9781107415324.004

Safaat, N. (2011). Pemrograman Aplikasi Mobile Smartphone dan Tablet PC Berbasis Android. Bandung: Informatika Bandung. In Android.

Sugiyono. (2012). Metode Penelitian Kuantitatif, Kualitatif dan R \& D.Bandung:Alfabeta. Metode Penelitian Kuantitatif, Kualitatif Dan R \& D.Bandung:Alfabeta. https://doi.org/10.1017/CBO9781107415324.004

Suharyanto, C. E., Chandra, J. E., \& Gunawan, F. E. (2017). Perancangan Sistem Informasi Penggajian Terintegrasi Berbasis Web (Studi Kasus di Rumah Sakit St. Elisabeth). Jurnal Nasional Teknologi Dan Sistem Informasi. https://doi.org/10.25077/teknosi.v3i2.2017.225-232 